\title{
Investigation into Hypoglycemic, Antihyperlipidemic, and Renoprotective Potentials of Dennettia tripetala (Pepper Fruit) Seed in a Rat Model of Diabetes
}

\author{
Innocent Anioke, ${ }^{1}$ Chukwugozie Okwuosa, ${ }^{1}$ Ikenna Uchendu, ${ }^{1}$ Olive Chijioke, ${ }^{1}$ \\ Ogechukwu Dozie-Nwakile, ${ }^{1}$ Ifeoma Ikegwuonu, ${ }^{1}$ Peculiar Kalu, ${ }^{2}$ and Maryann Okafor ${ }^{1}$ \\ ${ }^{1}$ Department of Medical Laboratory Sciences, Faculty of Health Sciences and Technology, College of Medicine, \\ University of Nigeria, Enugu Campus, Enugu, Nigeria \\ ${ }^{2}$ Department of Chemical Pathology, College of Medicine, Nnamdi Azikiwe University, Nnewi, Nigeria
}

Correspondence should be addressed to Innocent Anioke; innocent.anioke@unn.edu.ng

Received 20 April 2017; Accepted 9 August 2017; Published 17 October 2017

Academic Editor: Naoaki Sakata

Copyright (C) 2017 Innocent Anioke et al. This is an open access article distributed under the Creative Commons Attribution License, which permits unrestricted use, distribution, and reproduction in any medium, provided the original work is properly cited.

\begin{abstract}
This study investigated the hypoglycemic, antihyperlipidemic, and renoprotective potentials of Dennettia tripetala (DT) in a rat model of diabetes. The hypoglycemic activity in crude methanol seed extract of DT (CMEDT) and methanol seed fraction of DT (MFDT) measured by glucose oxidase method was increased by $47.37 \%$ and $28.72 \%$, respectively, after 8 hours of administration. After 10 days of treatment, CMEDT and MFDT gave a good glycemic control with the highest percentage reduction of $75.82 \%$ and $71.34 \%$ in glucose level, respectively, which is closely compared with $79.91 \%$ in glibenclamide. Using the enzymatic assay and Friedewald's equation, there was a significant reduction in serum level of total cholesterol (TC), triglyceride (TG), very-low-density lipoprotein (VLDL), and low-density lipoprotein (LDL) and a significant increase in high-density lipoprotein (HDL) $(p<0.05)$ following treatment with CMEDT and MFDT, when compared with the untreated group, although results varied in dosed groups, with high dose of MFDT showing a better lipid-lowering activity. High dose of MFDT improved lipid metabolism and increased percentage protection against atherogenesis by 44\%. However, neither CMEDT nor MFDT ameliorated the renal biochemical alteration in urea and creatinine. Thus, the study demonstrates hypoglycemic and antihyperlipidemic potentials of DT seed in diabetes.
\end{abstract}

\section{Introduction}

Diabetes mellitus (DM) is a chronic metabolic disorder of impaired carbohydrates, fat, and protein metabolism, characterized by hyperglycemia, polyuria, polydipsia, weight loss, polyphagia, and glycosuria due to insulin deficiency. This could be secondary to reduced insulin production by the pancreas or lack of response to insulin by target tissues such as the liver, adipose tissue, and skeletal muscle $[1,2]$. Typical metabolic derangement in diabetes involves decreased utilization of carbohydrates, excessive glycogenolysis, and increased gluconeogenesis from amino acids and fatty acids $[3,4]$. Diabetes may be acquired or hereditary.

In 2010, about 285 million diabetic cases were reported, representing $6.4 \%$ of the adults globally, and this is expected to increase to about 439 million adults (7.7\%) by 2030 [5]. In the past decades, the prevalence of DM in Nigeria was $2.2 \%$ [6]. In the recent past, this has increased to $5.0 \%$ [7] whereas about $6.7 \%$ prevalence rate of type 2 diabetes has been documented in Southeast Nigeria [8]. In Africa, where access to quality healthcare services is limited, Nigeria specifically has the highest burden of DM $[7,9,10]$. For instance, Ogbera et al. [9] reported that DM cases account for approximately $15 \%$ of all medical admissions and $22 \%$ of all medical deaths in Nigerian hospitals. This evidence demonstrates a critical health challenge for DM cases in Nigeria.

Along with hyperglycemia (which causes glycation of proteins) and dyslipidemia, diabetes is associated with microand macrovascular complications affecting several organs of the body [11-13]. All DM patients have at least one type of 


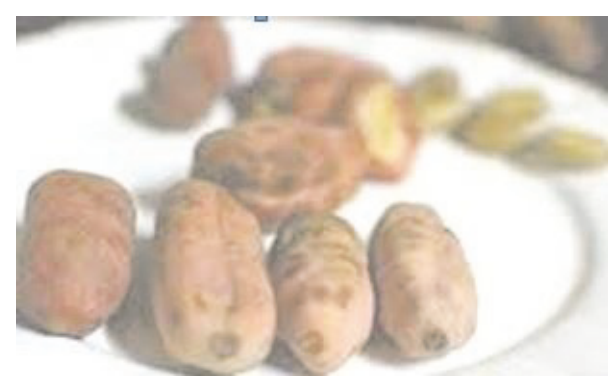

FIgURE 1: Dennettia tripetala fruits.

dyslipidemia whereas others have combined dyslipidemia, which is characterized by a reduction in high-density lipoprotein (HDL) level and elevation in low-density lipoprotein (LDL) and triglyceride (TG) levels $[10,14]$. These lipoprotein disturbances constitute a major risk factor for coronary heart disease (CHD) which is a cause of morbidity and mortality in patients [15]. While there are various pathophysiological mechanisms leading to diabetic nephropathy (DNP) [16-19], the formation of advanced glycation end products induced by chronic hyperglycemia and dyslipidemia is considered to play a vital role in the progression of DNP [20, 21].

Given that DM is a multifactorial disease, the treatment strategy should focus not only on maintaining a tight control of blood glucose level within the normal limit, but also on correcting the associated metabolic defects [22] such as dyslipidemia, all of which are implicated in the development of DNP [23-25].

During the past decade, herbal medicine has been gaining popularity exponentially both in developing and in developed countries. As such, in traditional practice, in many countries, herbal remedies have been employed in treatment and management of DM [26]. Perhaps, as herbal drugs have been associated with minimal side effects besides their perceived effectiveness [27, 28], the WHO recommends their use for the treatment of DM [29]. Furthermore, according to the Indian Council of Medical Research (ICMR), there is no satisfactory treatment yet for DM using allopathic drugs, which therefore underpins the investigation of suitable herbal therapy $[26,30]$.

Unsurprisingly, there are many herbal remedies suggested for the treatment of diabetes [31-33], which clinical investigations are yet to confirm most, for their efficiency and safety. One such dietary plant product is Dennettia tripetala (Annonaceae) (Figure 1), which is widely consumed in Southern Nigeria. It is found in the tropical rainforest region of Nigeria and sometimes in Savana areas [34]. Locally, it is known as "Nkarika" (in Efiks of Calabar), "Nmimi” (in Igbo), and "Igbere" (in Yoruba). The mature fruits have a spicy taste and constitute the main edible portions [35]. The leaves and roots are utilized, in addition to the fruits, for medicinal purposes, especially in the southern part of Nigeria [36].

Dennettia tripetala (pepper fruit) is believed to be endowed with hypoglycemic potentials. However, there is no documented report to the best of the researchers' knowledge on the antidiabetic and specifically on the antihyperlipidemic effect of the seed extract of D. tripetala at the time of this study. Therefore, the study was designed to investigate the hypoglycemic, antihyperlipidemic, and renoprotective effect of Dennettia tripetala (DT) seed using a rat model of diabetes. The outcome of this study would eventually be useful in the management of DM in humans later on, if found to reverse major metabolic alterations (e.g., hyperglycemia, hyperlipidemia, and abnormal renal biochemistry) associated with DM.

\section{Materials and Methods}

2.1. Collection and Authentication of Plant Material. Fresh samples of ripe and unripe D. tripetala fruits were purchased from the main market in Enugu, Enugu State, Nigeria. The plant material was authenticated by a consultant taxonomist at the herbarium section of the Department of Plant Science and Biotechnology, University of Nigeria, Nsukka, and a voucher specimen was deposited at the herbarium with reference number $\mathrm{UNH} 8^{\mathrm{C}}$ for future reference.

\subsection{Processing of Dennettia tripetala Seed Powder. Dennettia} tripetala seeds were steeped in water for 24 hours to loosen the bark. After dehulling, the seeds were washed three times with clean water to remove debris and sand and then dried under the shade (below $40^{\circ} \mathrm{C}$ ). The dried seeds were milled with an electric blender and finally ground into powder using a hammer mill (500\# grinder/Fuyu Metal, Linyi Fuyu Metal Products Co., Ltd., China) and thereafter passed through a $200 \times 50 \mathrm{~mm}$ sieve (Retsch GmbH, Germany).

2.3. Chemicals and Reagents. Streptozotocin was purchased from Sigma-Aldrich Ltd., United Kingdom (UK), while Clamide (glibenclamide) manufactured by Hovid Berhad (121 Jalan Tunku Abdul Rahman, 30010 Ipoh, Malaysia) was purchased from Enugu. The commercial kits for creatinine, urea, and lipid profiles estimation were purchased from Randox Laboratory, United Kingdom. Other reagents and chemicals were obtained from research laboratories in Enugu. All the chemicals used were of analytical grade, while the water was glass-distilled.

\subsection{Preparation of the Crude Methanol Extract and Fraction.} The powdered seeds (1500 g) of Dennettia tripetala were weighed and macerated in 2.5 liters of absolute methanol in a 10-liter container and left for 48 hours. The mixture, intermittently, was agitated during the extraction process. After 48 hours, the mixture was sieved using muslin cloth and filtered with Whatman No. 1 filter paper and the filtrate then evaporated to dryness on a rotary evaporator. The residue obtained was labeled as the crude methanol extract (CMEDT) and stored in a refrigerator at $4 \pm 2^{\circ} \mathrm{C}$ until required. The marc was allowed to air-dry on McIntosh. The dried marc was reweighed and further extracted in $\mathrm{N}$ hexane and ethyl acetate solvents, respectively, in that order of increasing solubility gradient. The marc obtained after the extractions was spread out on McIntosh and allowed to air-dry in a rotary evaporator (BUCHI Rotavapor R-215, Switzerland). The dried marc was reweighed and macerated 
in 2.5 liters of methanol for 48 hours. After 48 hours, the mixture was treated in a similar fashion as above while the residue obtained was labeled as methanol fraction (MFDT) and kept in a refrigerator at $4 \pm 2^{\circ} \mathrm{C}$ until required.

2.5. Determination of the Extractive Value for the Crude Methanol Seed Extract and Fractions. The concentrations of the CMEDT and MFDT were determined by evaporating $1 \mathrm{ml}$ each of the residue in an evaporating dish of known weight in an oven (Gallen Kamp, UK) to dryness at $70^{\circ} \mathrm{C}$. The dish containing the residue was allowed to cool and the weight of the residue was obtained by subtracting the weight of the empty dish from the weight of the dish and residue. The above process was done in duplicate, and the average weights were taken. The dry residue was then weighed to obtain the concentration which is expressed in $\mathrm{g} / \mathrm{ml}$. The residues of CMEDT and MFDT gave a concentration of $0.6 \mathrm{~g} / \mathrm{ml}$ and $0.8 \mathrm{~g} / \mathrm{ml}$, respectively. The appropriate concentration then was calculated and reconstituted with water prior to administration.

2.6. Phytochemical Analysis. Standard procedures as described by Sofowora [37], Trease and Evans [38], and Harborne [39] were used to identify the bioactive chemical constituents present in DT seeds using appropriate chemical tests for the screening and identification process.

\subsection{Experimental Animals}

2.7.1. Animal Housing and Management. A total of 56 apparently healthy albino rats of same sex and age weighing between $100 \mathrm{~g}$ and $150 \mathrm{~g}$ were obtained from Animal House of the College of Medicine, University of Nigeria Teaching Hospital, Enugu. The rats were divided into seven (7) groups of eight (8) rats each. They were acclimatized for a period of two (2) weeks in clean gauzed cages according to their body weight $(x \pm 20 \mathrm{~g})$ under good laboratory conditions at the Animal House of the College of Medicine, University of Nigeria, Enugu Campus. They were also fed with commercial standard pellets (Topfeed ${ }^{\circledR}$, Nigeria) and clean water was provided daily ad libitum. Handling, management, and use of animals for the experiment followed the "Ethical and Scientific Considerations Regarding Animal Testing and Research" [40].

2.8. Acute Toxicity (Median Lethal Dose, $L d_{50}$ ). The oral median lethal dose of CMEDT and MFDT was determined in rats as described by Lorke [41].

2.9. Induction of Diabetes. Streptozotocin ( $100 \mathrm{mg}$ ) was freshly dissolved in $1 \mathrm{ml}$ of $0.1 \mathrm{M}$ citrate buffer $(\mathrm{pH} 4.5)$ and was administered to various groups, based on the body weight of the rats and at a dosage of $45 \mathrm{mg} / \mathrm{kg}$ body weight. The administration was done subcutaneously in vehicle volume of $0.07 \mathrm{ml}$ using a syringe with fine needle [42]. A rest period of two days ( 48 hours) following induction of diabetes was allowed for the blood glucose level to stabilize. During this period, the animals had free access to both water and food. Blood glucose was measured by a glucometer (One Touch Ultra ${ }^{\circledR}$, LifeScan, USA), and only rats with blood glucose $>200 \mathrm{mg} / \mathrm{dl}$ were considered hyperglycemic. The hyperglycemic rats $(n=30)$ were divided into 6 groups comprising 5 rats in each group for the study.

2.10. Clamide (Glibenclamide). Clamide acts on the $\beta$-cell membrane leading to the enhancement of the calcium flux across it, hence provoking the brisk release of insulin from the pancreas. Although the insulinemic action of Clamide declines after chronic administration, however, improvement in glucose tolerance is maintained, suggesting its efficient hypoglycemic action [43]. Clamide (glibenclamide) $(5 \mathrm{mg} \times$ 20 ), dissolved in distilled water and made up to $50 \mathrm{ml}$ giving a concentration of $2 \mathrm{mg} / \mathrm{ml}$, was used in the study as a standard antidiabetic drug.

2.11. Experimental Design. The rats were divided into the following groups:

Group A received $50 \mathrm{mg} / \mathrm{kg}$ body weight of CMEDT. Group B received $100 \mathrm{mg} / \mathrm{kg}$ body weight of CMEDT. Group C received $50 \mathrm{mg} / \mathrm{kg}$ body weight of MFDT. Group D received $100 \mathrm{mg} / \mathrm{kg}$ body weight of MFDT. Group E (diabetic positive control) received $10 \mathrm{mg} / \mathrm{kg}$ glibenclamide, the standard DM drug.

Group F (diabetic negative control) received the vehicle for reconstitution.

Group G was normal control.

2.12. Acute Study. All the diabetic animals were made to fast overnight (12 hrs) and fasting blood glucose level was determined (at $0 \mathrm{hrs}$ ) before which the extracts and fraction were administered through the oral gavages. The blood glucose concentration was estimated at $2 \mathrm{hrs}, 4 \mathrm{hrs}$, and $8 \mathrm{hrs}$, respectively, after the administration for the acute study.

2.13. Subacute Study. The second phase (subacute study) began with oral gavages of the extract and fraction twice daily for ten (10) days. Body weights were measured on the 0th day and 10th day of the experiment. Fasting blood glucose was estimated on the 5th day and 10th day, respectively. After the 10th day of treatment with DT, the experiment was terminated and blood samples were collected.

2.14. Collection of Blood from Animals. The blood sample used for biochemical analysis was collected through the median canthus of the eye under ether anesthesia using capillary tube into plain tubes. The blood was centrifuged to separate serum for estimation of glucose, lipid profile, urea, and creatinine.

2.15. Biochemical Analyses. Blood glucose level was measured using the glucose oxidase method [44].

Renal biochemical parameters: creatinine was estimated by Jaffe method while urea was measured by diacetyl monoxime (DAM) method.

Measurement of serum lipid profile was carried out using enzymatic end point (kit) methods:

Triglycerides: glycerol-phosphate oxidase (GPOD) method [45] 
TABLE 1: Hypoglycemic (acute) effect of crude methanol seed extract and fraction (CMEDT and MFDT) in streptozotocin-induced diabetic rats.

\begin{tabular}{|c|c|c|c|c|c|c|}
\hline \multirow{2}{*}{ Group } & \multirow{2}{*}{ Treatment (twice daily) } & \multicolumn{4}{|c|}{ Plasma glucose concentration $(\mathrm{mg} / \mathrm{dl})$} & \multirow{2}{*}{$\%$ reduction } \\
\hline & & 0 hours & 2 hours & 4 hours & 8 hours & \\
\hline A & $\begin{array}{c}\text { CMEDT } \\
50 \mathrm{mg} / \mathrm{kg} \text { body weight }\end{array}$ & $413.6 \pm 39.44$ & $315.60 \pm 9.55$ & $320.80 \pm 10.29$ & $217.60 \pm 12.00$ & $47.37^{*}$ \\
\hline B & $\begin{array}{c}\text { CMEDT } \\
100 \mathrm{mg} / \mathrm{kg} \text { body weight }\end{array}$ & $326.60 \pm 19.84$ & $377.20 \pm 6.86$ & $372.40 \pm 34.54$ & $335.60 \pm 4.65$ & -2.76 \\
\hline $\mathrm{C}$ & $\begin{array}{c}\text { MFDT } \\
50 \mathrm{mg} / \mathrm{kg} \text { body weight }\end{array}$ & $563.40 \pm 28.43$ & $413.40 \pm 7.59$ & $432.60 \pm 29.15$ & $401.60 \pm 62.22$ & $28.72^{*}$ \\
\hline $\mathrm{D}$ & $\begin{array}{c}\text { MFDT } \\
100 \mathrm{mg} / \mathrm{kg} \text { body weight }\end{array}$ & $367.80 \pm 21.26$ & $455.20 \pm 64.25$ & $522.20 \pm 60.81$ & $329.60 \pm 29.15$ & 10.39 \\
\hline $\mathrm{E}$ & $\begin{array}{l}\text { Glibenclamide } 10 \mathrm{mg} / \mathrm{kg} \text { body weight } \\
\text { (positive control) }\end{array}$ & $517.80 \pm 32.66$ & $451.60 \pm 25.39$ & $441.40 \pm 16.90$ & $343.40 \pm 0.87$ & $33.70^{*}$ \\
\hline $\mathrm{F}$ & Negative (untreated) control & $342.00 \pm 37.15$ & $446.40 \pm 45.46$ & $523.60 \pm 32.35$ & $487.80 \pm 37.24$ & -42.63 \\
\hline G & Normal control & $104.00 \pm 6.79$ & $90.40 \pm 1.63$ & $101.60 \pm 1.03$ & $87.20 \pm 4.57$ & 16.15 \\
\hline
\end{tabular}

Values are mean $\pm \operatorname{SEM} ; n=5 ;{ }^{*} \%$ reduction in plasma glucose level as compared to zero hours after 8 hours.

Total cholesterol: cholesterol oxidase method (CHOD) [46] and HDL cholesterol: precipitation methods [47]

Friedewald equation was applied for low-density lipoprotein (LDL) cholesterol and very-low-density lipoprotein (VLDL) estimation: LDL cholesterol = total cholesterol (triglycerides/5 + HDL cholesterol), where TG/5 = VLDL.

Atherogenic index and percentage protection of DT were estimated using the formulae described by $\mathrm{Ng}$ et al. [48]:

Atherogenic index (AI)

$$
=\frac{(\text { total cholesterol }- \text { HDL cholesterol })}{\text { HDL }} ;
$$

Protection $\%=\mathrm{AI}($ control $)-\frac{\mathrm{AI} \text { (treated) }}{\mathrm{AI}(\text { control })} \times 100$.

2.16. Data Analysis. Data were collected using an appropriate laboratory test method for each biochemical parameter as described above. All data were analyzed using SPSS software (version 22) and results were expressed as mean \pm SEM. One-way analysis of variance (ANOVA) followed by post hoc multiple comparison tests was used to compare group means. $p<0.05$ was considered to be a statistically significant value.

\section{Results}

3.1. Acute Toxicity Test. There was no mortality or any signs of behavioral changes or toxicity observed after the administration, suggesting that CMEDT and MFDT have a high degree of safety in Wistar albino rats.

3.2. Blood Glucose and Body Weight. Table 1 shows that, in the treatment groups $\mathrm{A}$ and $\mathrm{C}$, there was a significantly decreased $(p<0.05)$ plasma glucose level after 8 hours of extract administration when compared with 0 hrs. Although the percentage reduction was the highest in group A (47.37\%) as opposed to group $\mathrm{E}(33.70 \%)$, however, it still indicates a potential antihyperglycemic action of CMEDT which may be similar to the standard antidiabetic drug, glibenclamide.

In Table 2, after day 10, there were significantly decreased $(p<0.05)$ plasma glucose levels in A, B, D, and E when compared with F (untreated control), respectively. However, there were no significant differences $(p>0.05)$ in plasma glucose levels when dosed groups were compared with the normal control $(\mathrm{G})$, respectively. This indicates a good glycemic control of CMEDT and MFDT, given that reduction in plasma glucose is closely the same as that of nondiabetic group G. Group A showed the highest percentage reduction $(75.82 \%)$ in blood glucose level followed by group $\mathrm{D}$ (71.34\%) which is pretty the same as group E (79.91\%) treated with glibenclamide. This indicates an efficient hypoglycemic action of CMEDT and MFDT. In relation to final body weights, there was a significant increase in body weights in groups $\mathrm{A}$ and $\mathrm{D}$ when compared with the negative (untreated) control, group F.

3.3. Serum Lipid Profile. Taken together, in Table 3, a significant reduction in serum level of TC, TG, VLDL, and LDL and a significant increase in HDL were observed following treatment with CMEDT and MFDT, though results varied in dosed groups. High-dose MFDT (group D) showed similar results to glibenclamide, a standard antidiabetic drug (group E), in all parameters except in TC which did not significantly decrease as opposed to the untreated group F. With lowdose CMEDT (group A), other parameters except HDL and LDL showed a similar trend to glibenclamide (group E). This indicates that low-dose CMEDT and more specifically highdose MFDT have potential antihyperlipidemic activity which is closely compared with that of glibenclamide, the standard antidiabetic drug.

3.4. Atherogenic Index and Percentage Protection. Table 4 shows atherogenic index (\% protection) of 2.33 (39\%) and 2.15 (44\%) at doses of $100 \mathrm{mg} / \mathrm{kg}$ body weight CMEDT (group B) and $100 \mathrm{mg} / \mathrm{kg}$ body weight MFDT (group D), respectively. In group $\mathrm{D}$, percentage protection $(44 \%)$ was found to be 
TABLE 2: Subacute effect of crude methanol seed extract and fraction (CMEDT and MFDT) on plasma glucose level and body weight in streptozotocin-induced diabetic rats.

\begin{tabular}{|c|c|c|c|c|c|c|c|}
\hline \multirow{2}{*}{$\begin{array}{l}\text { Group treatment } \\
\text { (twice daily) }\end{array}$} & \multirow{2}{*}{$\begin{array}{l}\text { Initial body weight } \\
\text { (g) Day } 0\end{array}$} & \multirow{2}{*}{$\begin{array}{l}\text { Final body weight } \\
\text { (g) Day } 10\end{array}$} & \multicolumn{3}{|c|}{ Plasma glucose concentration (mg/dl) } & \multicolumn{2}{|c|}{$\%$ reduction } \\
\hline & & & Day 0 & Day 5 & Day 10 & Body weight & Glucose level \\
\hline $\begin{array}{l}\text { A: CMEDT } \\
50 \mathrm{mg} / \mathrm{kg} \text { body } \\
\text { weight }\end{array}$ & $142.00 \pm 5.83$ & $90.00 \pm 4.47^{* *} \uparrow$ & $413.60 \pm 39.44$ & $117.20 \pm 24.01$ & $100.00 \pm 3.67^{* *} \downarrow$ & 36.62 & $75.82^{\mathrm{a}}$ \\
\hline $\begin{array}{l}\text { B: CMEDT } \\
100 \mathrm{mg} / \mathrm{kg} \text { body } \\
\text { weight }\end{array}$ & $124.00 \pm 6.78$ & $66.00 \pm 8.12$ & $326.60 \pm 19.84$ & $175.20 \pm 47.28$ & $183.60 \pm 38.21^{* *} \downarrow$ & 46.77 & $43.78^{\mathrm{a}}$ \\
\hline $\begin{array}{l}\text { C: MFDT } 50 \mathrm{mg} / \mathrm{kg} \\
\text { body weight }\end{array}$ & $104.00 \pm 2.45$ & $60.00 \pm 5.48$ & $563.40 \pm 28.43$ & $344.00 \pm 16.33$ & $327.60 \pm 19.42$ & 42.31 & $41.85^{\mathrm{a}}$ \\
\hline $\begin{array}{l}\text { D: MFDT } \\
100 \mathrm{mg} / \mathrm{kg} \text { body } \\
\text { weight }\end{array}$ & $122.00 \pm 7.35$ & $94.00 \pm 4.00^{* *} \uparrow$ & $367.80 \pm 21.26$ & $242.40 \pm 56.58$ & $105.40 \pm 11.27^{* *} \downarrow$ & 22.95 & $71.34^{\mathrm{a}}$ \\
\hline $\begin{array}{l}\text { E: glibenclamide } \\
10 \mathrm{mg} / \mathrm{kg} \text { body } \\
\text { weight (positive } \\
\text { control) }\end{array}$ & $114.00 \pm 2.45$ & $86.00 \pm 4.00$ & $517.80 \pm 32.66$ & $344.00 \pm 2.45$ & $104.00 \pm 2.07^{* *} \downarrow$ & 24.56 & $79.91^{\mathrm{a}}$ \\
\hline $\begin{array}{l}\text { F: negative } \\
\text { (untreated) control }\end{array}$ & $90.00 \pm 4.47$ & $66.00 \pm 2.45^{*} \downarrow$ & $342.00 \pm 37.15$ & $342.20 \pm 20.32$ & $414.20 \pm 26.28^{*} \uparrow$ & 26.67 & -21.11 \\
\hline G: normal control & $124.00 \pm 6.78$ & $122.00 \pm 3.74$ & $104.00 \pm 6.79$ & $75.00 \pm 3.27$ & $89.80 \pm 5.59$ & 1.61 & 13.65 \\
\hline$F$-ratio & 9.107 & 19.484 & 27.475 & 13.625 & 44.391 & & \\
\hline$p$ value & 0.000 & 0.000 & 0.000 & 0.000 & 0.000 & & \\
\hline
\end{tabular}

TABLE 3: Antihyperlipidemic effect of crude methanol seed extract and fraction (CMEDT and MFDT) in streptozotocin-induced diabetic rats.

\begin{tabular}{|c|c|c|c|c|c|c|}
\hline \multirow{2}{*}{ Group } & \multirow{2}{*}{$\begin{array}{l}\text { Treatment } \\
\text { (twice daily) }\end{array}$} & \multicolumn{5}{|c|}{ Changes in serum lipid profile in $\mathrm{mg} / \mathrm{dl}$} \\
\hline & & T. chol. & TG & HDL & LDL & VLDL \\
\hline A & $\begin{array}{c}\text { CMEDT } \\
50 \mathrm{mg} / \mathrm{kg} \text { body } \\
\text { weight }\end{array}$ & $104.20 \pm 31.83^{* *} \downarrow$ & $75.16 \pm 4.39^{* *} \downarrow$ & $26.22 \pm 0.30$ & $62.95 \pm 2.41$ & $15.03 \pm 0.88^{* *} \downarrow$ \\
\hline B & $\begin{array}{c}\text { CMEDT } \\
100 \mathrm{mg} / \mathrm{kg} \text { body } \\
\text { weight }\end{array}$ & $110.80 \pm 4.72$ & $85.34 \pm 4.83$ & $33.32 \pm 1.59^{* *} \uparrow$ & $60.41 \pm 5.11$ & $17.07 \pm 0.97$ \\
\hline $\mathrm{C}$ & $\begin{array}{c}\text { MFDT } \\
50 \mathrm{mg} / \mathrm{kg} \text { body } \\
\text { weight }\end{array}$ & $111.40 \pm 3.71$ & $79.06 \pm 5.288^{* *} \downarrow$ & $25.56 \pm 2.47$ & $70.03 \pm 4.81$ & $15.81 \pm 1.06^{* *} \downarrow$ \\
\hline $\mathrm{D}$ & $\begin{array}{c}\text { MFDT } \\
100 \mathrm{mg} / \mathrm{kg} \text { body } \\
\text { weight }\end{array}$ & $106.40 \pm 3.67$ & $78.28 \pm 3.78^{* *} \downarrow$ & $33.82 \pm 1.77^{* *} \uparrow$ & $56.92 \pm 2.17^{* *} \downarrow$ & $15.66 \pm 0.76^{* *} \downarrow$ \\
\hline $\mathrm{E}$ & $\begin{array}{l}\text { Glibenclamide } \\
10 \mathrm{mg} / \mathrm{kg} \text { body } \\
\text { weight (positive } \\
\text { control) }\end{array}$ & $101.20 \pm 1.24^{* *} \downarrow$ & $69.40 \pm 1.75^{* *} \downarrow$ & $34.04 \pm 2.48^{* *} \uparrow$ & $53.28 \pm 1.19^{* *} \downarrow$ & $13.88 \pm 0.35^{* *} \downarrow$ \\
\hline $\mathrm{F}$ & $\begin{array}{c}\text { Negative } \\
\text { (untreated) } \\
\text { control }\end{array}$ & $121.20 \pm 4.14^{*} \uparrow$ & $97.00 \pm 3.19^{*} \uparrow$ & $25.20 \pm 0.40^{*} \uparrow$ & $76.60 \pm 4.22^{*} \uparrow$ & $19.40 \pm 0.64^{*} \uparrow$ \\
\hline G & Normal control & $89.20 \pm 4.69$ & $76.00 \pm 2.45$ & $36.40 \pm 1.70$ & $37.60 \pm 5.84$ & $15.20 \pm 0.49$ \\
\hline & $F$-ratio & 7.374 & 5.303 & 7.595 & 9.705 & 5.303 \\
\hline & $p$ value & 0.000 & 0.001 & 0.000 & 0.000 & 0.001 \\
\hline
\end{tabular}

Values are mean \pm SEM; $n=5 ;{ }^{*} p<0.05$ when compared with normal control; ${ }^{* *} p<0.05$ when compared with negative (untreated) control. $\downarrow$ and $\uparrow$ : decrease and increase. 
TABLE 4: Atherogenic index and percentage protection of CMEDT and MFDT.

\begin{tabular}{|c|c|c|c|c|c|}
\hline \multirow{2}{*}{ Group } & \multirow{2}{*}{$\begin{array}{l}\text { Treatment } \\
\text { (twice daily) }\end{array}$} & \multicolumn{2}{|c|}{ Changes in serum lipid profile in $\mathrm{mg} / \mathrm{dl}$} & \multirow{2}{*}{ Atherogenic index (AI) } & \multirow{2}{*}{$\%$ protection } \\
\hline & & T. chol. & HDL & & \\
\hline A & $\begin{array}{c}\text { CMEDT } \\
50 \mathrm{mg} / \mathrm{kg} \text { body } \\
\text { weight }\end{array}$ & $104.20 \pm 31.83$ & $26.22 \pm 0.30$ & 2.97 & 22.01 \\
\hline B & $\begin{array}{c}\text { CMEDT } \\
100 \mathrm{mg} / \mathrm{kg} \\
\text { body weight }\end{array}$ & $110.80 \pm 4.72$ & $33.32 \pm 1.59$ & 2.33 & $38.85^{*}$ \\
\hline $\mathrm{C}$ & $\begin{array}{c}\text { MFDT } \\
50 \mathrm{mg} / \mathrm{kg} \text { body } \\
\text { weight }\end{array}$ & $111.40 \pm 3.71$ & $25.56 \pm 2.47$ & 3.36 & 11.81 \\
\hline $\mathrm{D}$ & $\begin{array}{c}\text { MFDT } \\
100 \mathrm{mg} / \mathrm{kg} \\
\text { body weight }\end{array}$ & $106.40 \pm 3.67$ & $33.82 \pm 1.77$ & 2.15 & $43.57^{*}$ \\
\hline $\mathrm{E}$ & $\begin{array}{c}\text { Glibenclamide } \\
10 \text { mg/kg body } \\
\text { weight } \\
\text { (positive } \\
\text { control) }\end{array}$ & $101.20 \pm 1.24$ & $34.04 \pm 2.48$ & 2.19 & $42.52^{*}$ \\
\hline $\mathrm{F}$ & $\begin{array}{c}\text { Negative } \\
\text { (untreated) } \\
\text { control }\end{array}$ & $121.20 \pm 4.14$ & $25.20 \pm 0.40$ & 3.81 & 0 \\
\hline G & $\begin{array}{l}\text { Normal } \\
\text { control }\end{array}$ & $89.20 \pm 4.69$ & $36.40 \pm 1.70$ & 1.98 & 48.03 \\
\hline
\end{tabular}

Values are mean \pm SEM $n=5 ;{ }^{*} \%$ protection as compared to untreated control group.

closely compared with that of glibenclamide (group E) at $10 \mathrm{mg} / \mathrm{kg}$ body weight (43\%), suggesting that DT may possess an antiatherogenic potential that is similar to glibenclamide.

3.5. Urea and Creatinine. In Table 5, the mean urea levels in groups D and E were significantly increased $(p<0.05)$ when compared with untreated group F, respectively, while creatinine in all dosed groups showed no significant difference $(p>0.05)$ when compared with group F. This suggests that treatment with DT may not positively protect against DNP.

3.6. Phytochemistry Analysis. In Table 6, the phytochemical analysis revealed the presence of bioactive phyto- and biochemical components that adapt DT for its nutritional and therapeutic purposes.

\section{Discussion}

In DM, the major metabolic derangements resulting from insulin deficiency or insensitivity are impaired glucose utilization and altered lipid and protein metabolism [15, 49]. Consequently, the outcome of rapid mobilization of triglycerides, for instance, is usually the elevated levels of free fatty acids in the plasma. This reduces glucose uptake and suppresses glucose metabolism in peripheral tissues (adipose tissue and skeletal muscle), further exacerbating hyperglycemia [49]. The driving force behind this metabolic alteration of these major energy molecules is attributed to the changes in the activities of molecular targets (or specific proteins or enzymes) involved in glucose/lipid metabolism or glucose transport in target tissues [50]. For instance, impaired glucose utilization and insulin deficiency decrease the expression of a number of proteins such as glucokinase and the GLUT4 glucose transporter gene required for normal response to insulin in liver and adipose tissue, respectively [49].

Antidiabetic drugs improve glucose homeostasis through modulation of these molecular targets $[51,52]$. Unfortunately, most synthetic agents such as sulfonylureas (e.g., glimepiride) and meglitinides (e.g., repaglinide) impact a single target [53], without producing a balanced therapeutic effect addressing the cascade of interrelated metabolic derangements such as hyperlipidemia [54]. However, thiazolidinediones (e.g., pioglitazone), a relatively new class of drugs, improve insulin sensitivity in target tissues by binding to and altering the function of a nuclear receptor, peroxisome proliferatoractivated receptor-gamma (PPAR- $\gamma$ ) [52]. PPAR- $\gamma$ regulates the transcription of specific proteins involved in glucose metabolism (e.g., glucokinase and GLUT4 glucose transporter protein) and lipid metabolism (e.g., lipoprotein lipase and fatty acid transporter protein), as well as energy balance $[15,50-52]$. This suggests that thiazolidinediones as a single agent have the capacity to impact glucose and lipid metabolism [55]. Most of these popularly prescribed antidiabetic therapies have an excellent safety profile. However, their associated adverse effects, such as, but not limited to, headache, dizziness, diarrhea, nausea, and dyspepsia, vitamin B12 and folic acid deficiency, weight gain, hypoglycemia, fluid retention, and edema [51-53], are thought to be clinically relevant.

Therefore, the need for alternative complimentary agents with holistic therapeutic potential and minimal side effects 
TABLE 5: Effect of crude methanol seed extract and fraction (CMEDT and MFDT) on kidney function parameters in streptozotocin-induced diabetic rats.

\begin{tabular}{lcc}
\hline Group & Treatment (twice daily) & Changes in serum urea/creatinine \\
Creatinine $(\mu \mathrm{mol} / / \mathrm{l})$
\end{tabular}

Values are mean \pm SEM; $n=5 ;{ }^{*} p<0.05$ when compared with normal control; ${ }^{* *} p<0.05$ when compared with negative (untreated) control. $\downarrow$ and $\uparrow$ : decrease and increase.

TABLE 6: Phytochemical analysis result of Dennettia tripetala seed.

\begin{tabular}{lc}
\hline Constituents & Inference \\
\hline Flavonoids & - \\
Antraquinone glycosides & - \\
Anthracene glycosides & - \\
Alkaloids & +++ \\
Saponins & +++ \\
Tannins & - \\
Resins & + \\
Proteins & + \\
Carbohydrate & +++ \\
Reducing sugars & +++ \\
Hydrolysis test for glycosides & ++ \\
Cyanogenetic glycosides & - \\
Fat \& oils & - \\
Steroids & - \\
Terpenoids & - \\
Acidic compounds & Neutral \\
Cardiac digitoxose & - \\
\hline
\end{tabular}

Key. -: absent; +: present; ++: moderately present; +++: abundantly present.

has been an important growing consideration in DM management over the past decade [56]. Moreover, effective oral antidiabetic drugs should have an impact on lipid metabolism beyond the expected effects on glycemic control [56]. Additionally, Unnikrishnan et al. [54] underpinned the need to identify natural agents with a more holistic mechanism of action, without disturbing the physiological equilibrium of the patients.

In light of the current study, DT has emerged as a potential alternative antidiabetic agent from natural origin with such therapeutic impact. The use of a single natural agent such as DT will possibly ensure increased patient convenience and the potential for increased compliance to therapy. DT may have exerted a multimodal effect, which is moderate and spreads over different targets tissues, thereby modulating several cascading effects on glucose and lipid metabolism triggered by DM, to improve glucose homeostasis.

4.1. Effect of DT on Blood Glucose and Body Weight. In the present study, treatment with low-dose CMEDT $(50 \mathrm{mg} / \mathrm{kg}$ body weight) and high-dose MFDT (100 mg/kg body weight) produced a significant decrease in plasma glucose level closely compared to glibenclamide at $10 \mathrm{mg} / \mathrm{kg}$ body weight. Glibenclamide acts on the $\beta$-cell membrane which enhances calcium influx across it, thereby provoking the brisk release of insulin from the pancreas leading to increased glucose utilization and hence decreased plasma glucose $[43,57,58]$. The phytochemical investigation of DT seed carried out in the current study revealed the presence of saponins, resins, alkaloids, and so forth. Studies in the recent past [59-64] reported that dietary flavonoids, alkaloids, saponins, tannins, and glycosides have antidiabetic potentials. These bioactive phytochemicals, as reported in previous studies [65-68], may either singly or in synergy with one another be responsible for the significant glucose-lowering activity reported in the current study. Although the precise mechanism leading to the hypoglycemic effect was not elucidated in the study, the fact that the percentage glucose reduction noted at lowdose CMEDT (75.82\%) and high-dose MFDT (71.34\%) was closely compared with glibenclamide (79.91\%) suggests that the mechanism of action of DT and glibenclamide may be similar, which may be attributed to increased secretion of insulin from the $\beta$-cells of the pancreas. Additionally, other mechanisms may have played a role in the glucose-lowering 
effect following treatment with DT. For instance, glucose kinase (GK) is known to regulate as well as facilitate the glucose uptake/utilization in hyperglycemic state in the liver $[14,69]$. Grimsby et al. [70] suggested that, with the increase in GK activity, glucose utilization is often stimulated, leading to an increase in glycogen synthesis which in turn results in a significant plasma glucose reduction. A study in the recent past [71] underpinned the notion that hypoglycemia results with GK activator, as GK activity is increased with simultaneous conversion of plasma glucose to liver glycogen in diabetic patients. Although the activity of hepatic GK is not investigated in the current study, however, we suggest that DT could be a potential liver glucose kinase activator.

In streptozotocin-induced diabetic rats, body weight decreased significantly compared to the normal control, which may be attributed to increased degradation of structural protein due to damage to the intracellular signaling pathways implicated in maintaining the balance between protein synthesis and degradation $[72,73]$. Interestingly, there was a significant increase in the body weight when compared with the untreated (negative control) group after treatment. This suggests that DT may have a bioactive potency similar to IGF-1, which increases protein synthesis in diabetes to restore muscle wasting through the activation of Akt/mTOR pathways [74-77].

4.2. Effect of DT on Plasma Lipid Profile. According to documented evidence [78], abnormalities in insulin action or deficiency rather than chronic hyperglycemia per se significantly lead to increased plasma TC and TG seen in diabetic patients. In the absence of insulin, hypertriglyceridemia normatively occurs given that lipoprotein lipase (LpL) is not activated, an enzyme which is needed to hydrolyze TG $[14,79]$. There is closely linked bidirectional cholesterol exchange between HDL particle and TG-rich lipoproteins [14]. Kameswararao et al. [80] reported that maintenance of tight glycemia control results in significant reversal of lipid abnormalities associated with drug-induced diabetes in rats.

Interestingly, in the current study, the results indicate that low-dose CMEDT and more specifically high-dose MFDT reversed the diabetic dyslipidemia characterized with increased TG and decreased HDL associated with streptozotocin-induced diabetic rats noted in the diabetic control (untreated) group F. High-dose MFDT, however, showed a more effective antidyslipidemic potential closely compared with that of glibenclamide. This may be attributed to the brisk release of insulin from the pancreas activating the LpL which reduces TG through hydrolysis. Furthermore, the results suggest that DT may have reversed increased free fatty acids which affect adequate glucose metabolism in diabetic patients $[81,82]$. Presence of insulin stimulates fatty acids biosynthesis, incorporates fatty acids into TG in the liver and adipose tissue [83] by inhibiting hormone sensitive lipase (HSL), increases utilization of glucose, and decreases mobilization of free fatty acids from the fat depositions [84]. Apart from the aforementioned mechanism, it is speculated that DT may have inhibited the activity of plasma endothelial lipase (EL) involved in HDL metabolism, despite being not studied, thereby decreasing the phospholipase action of EL which derives HDL catabolism by hydrolyzing its phospholipids content [85-88]. Furthermore, the increase in HDL fraction may also be attributed to the inhibition of cholesteryl ester transfer protein (CETP) by DT, an enzyme that regulates the transfer of cholesterol ester from HDL to other fractions of plasma cholesterol, particularly TG lipoproteins [89]. It is possible that CMEDT and MFDT like some glucose-reducing agents (e.g., thiazolidinediones) may have improved insulin action on peripheral tissues leading to a greater improvement in lipid profile parameters $[90,91]$ reported in the current study.

Growing evidence suggests that diabetic dyslipidemia is closely associated with cardiovascular risk [14]. According to Panagiotakos et al. [92], diabetic patients at risk of cardiovascular diseases could be predicted using LDL/HDL ratio. This is referred to as the atherogenic index (AI), with an index of greater than 5 set as the cut-offs for at-risk patients [48]. Therefore, given that values of CMDT and MFDT in all dosed groups were less than $5(<5)$, it may be inferred that DT seeds have a cardiovascular protective potential besides its antihyperlipidemic potency.

4.3. Effect on Renal Biochemical Parameters. Following the induction of diabetes, the concentration of urea was significantly increased in untreated rats when compared with the normal control rats, suggesting renal involvement. Surprisingly, treatment with either CMDT or MFDT, at high or low dose, in all dosed groups was not found to produce significant reduction in urea when compared with the untreated group (diabetic control). Creatinine concentration showed no significant difference after treatment either, when compared with the untreated diabetic groups. This suggests that treatment with DT may not positively protect against diabetic nephropathy (DNP).

\section{Conclusion}

The present experimental study demonstrated hypoglycemic and antihyperlipidemic potency of Dennettia tripetala (pepper fruit) (DT) which is closely compared with glibenclamide in the treatment of diabetes. However, there is no evidence of renoprotective potential associated with DT in the study. The potential antidiabetic properties linked with DT need to be therapeutically maximized to ameliorate the burden of diabetes and its complications in the society. There is, therefore, the need for further investigation to elucidate the phytochemical component(s) present in DT seed with the antidiabetic property observed in the study.

\section{Conflicts of Interest}

The authors declare that there are no conflicts of interest regarding the publication of this paper.

\section{References}

[1] L. Ali, A. Kahn, and M. Mosihuzzaman, "Studies on the hypoglycemic effects of fruit pulp, seed and whole plant of Momordica cheranta on normal and diabetic rat model," Planta Medica, vol. 56, pp. 408-412, 1993. 
[2] T. Susheela, B. Padma, T. Jane, R. Narender, and P. Reddy, "Evaluation of hypoglycemic and anti-diabetic effect of Melia dubia fruit in mice," Current Science, vol. 94, no. 9, pp. 1191-1195, 2008.

[3] A. Pontiroli, A. Ealdera, and G. Pozza, "Diabetes," Metabolism Reveiws, vol. 10, article 31, 1994.

[4] G. Gruden, P. C. Perin, and G. Camussi, "Insight on the pathogenesis of diabetic nephropathy from the study of podocyte and mesangial cell biology," Current Diabetes Reviews, vol. 1, no. 1, pp. 27-40, 2005.

[5] J. Shaw, R. Sicree, and P. Zimmet, "Global estimates of the prevalence of diabetes for 2010 and 2030," Diabetes Research and Clinical Practice, vol. 87, pp. 4-14, 2010.

[6] O. Akinkugbe and O. Akinyanju, "Final report. National Survey on Non-Communicable Disease," Tech. Rep., Federal Ministry of Health, Lagos, Nigeria.

[7] R. Oputa and S. Chinenye, "Diabetes in Nigeria a translational medicine approach," African Journal of Diabetes Medicine, vol. 23, no. 1, pp. 7-10, 2015.

[8] C. U. Osuji, B. A. Nzerem, C. E. Dioka, S. C. Meludu, and E. I. Onwubuya, "Prevalence of diabetes mellitus in a group of women attending "August meeting" at Naze South East Nigeria," Journal of Diabetes Mellitus, vol. 02, no. 03, pp. 321326, 2012.

[9] A. O. Ogbera, S. Chinenye, A. Onyekwere, and O. Fasanmade, "Prognostic indices of diabetes mortality," Ethnicity and Disease, vol. 17, no. 4, pp. 721-725, 2007.

[10] O. A. Komolafe, D. O. Adeyemi, S. O. Adewole, and E. M. Obuotor, "Streptozotocin-induced diabetes alters the serum lipid profiles of adult wistar rats," The Internet Journal of Cardiovascular Research, vol. 7, no. 1, 2009.

[11] A. Ramachandra, C. Snehalata, and V. Vishwanathan, "Burden of Type 2 diabetes and it's complications-the Indian scenerio," Current Science, vol. 83, pp. 1471-1477, 2002.

[12] T. Merlin, T. Con, M. Richard, and J. George, "Anaemia in diabetes: an emerging complication of microvascular disease," Current Diabetes Reviews, vol. 1, pp. 107-126, 2005.

[13] M. J. Fowler, "Microvascular and macrovascular complications of diabetes," Clinical Diabetes, vol. 26, no. 2, pp. 77-82, 2008.

[14] J. Lee, H.-I. Lee, K.-I. Seo et al., "Effects of ursolic acid on glucose metabolism, the polyol pathway and dyslipidemia in nonobese type 2 diabetic mice," Indian Journal of Experimental Biology, vol. 52, no. 7, pp. 683-691, 2014.

[15] S. Raju and B. Raju, Illustrated Medical Biochemistry, Jaypee Brothers Medical Publishers, New Delhi, India, 2nd edition, 2010.

[16] E. Matteucci and O. Giampietro, "Oxidative stress in families of type 1 diabetic patients," Diabetes Care, vol. 23, no. 8, pp. 11821186, 2000.

[17] L. W. Oberley, "Free radicals and diabetes," Free Radical Biology and Medicine, vol. 5, no. 2, pp. 113-124, 1988.

[18] J. Baynes and S. Thorpe, "The role of oxidative stress in diabetic complications," Current Opinion in Endocrinology, vol. 3, pp. 277-284, 1997.

[19] B. Lipinski, "Pathophysiology of oxidative stress in diabetes mellitus," Journal of Diabetes and Its Complications, vol. 15, no. 4, pp. 203-210, 2001.

[20] R. MacIsaac and G. Jerums, "Management of early Diabetic Nephropathy," Diabetes Voice, vol. 48 (Special Issue), pp. 15-18, 2003.
[21] V. M. Altan, "The pharmacology of diabetic complications," Current Medicinal Chemistry, vol. 10, no. 15, pp. 1317-1327, 2003.

[22] A. Hattersley, "Multiple facts of diabetes in young people," Current Science, vol. 82, pp. 273-276, 2002.

[23] M. Ravid, L. Neumann, and M. Lishner, "Plasma lipids and the progression of nephropathy in diabetes mellitus type II: Effect of ACE inhibitors," Kidney International, vol. 47, no. 3, pp. 907910, 1995.

[24] M.-A. Gall, P. Hougaard, K. Borch-Johnsen, and H.-H. Parving, "Risk factors for development of incipient and overt diabetic nephropathy in patients with non-insulin dependent diabetes mellitus: prospective, observational study," British Medical Journal, vol. 314, no. 7083, pp. 783-788, 1997.

[25] R. Klein, B. E. K. Klein, S. E. Moss, K. J. Cruickshanks, and P. C. Brazy, "The 10-year incidence of renal insufficiency in people with type 1 diabetes," Diabetes Care, vol. 22, no. 5, pp. 743-751, 1999.

[26] T. Rosalind, K. Biman, and B. Satya, "Antihyperglycemic and Antihyperlipidemic activity of Ficus Auriculata lour leaf extract in streptozotocin in induced diabetic mice," World Journnal of Pharmacy and Pharmaceutical Sciences, vol. 3, no. 1, pp. 412-427, 2013.

[27] WHO, Regulatory Situation of Herbal Medicines: A Worldwide Review, World Health Organization, Geneva, Switzerland, 2013.

[28] B. Beyene, B. Beyene, and H. Deribe, "Review on application and management of medicinal plants for the livelihood of the local community," Journal of Resources Development and Management, vol. 22, pp. 33-39, 2016.

[29] WHO, "Expert Committee on Diabetes Mellitus," Technical Report Series, Geneva, Switzerland, 1980.

[30] L. Verma, A. Khatri, B. Kaushik, U. K. Patil, and R. S. Pawar, "Antidiabetic activity of Cassia occidentalis (Linn) in normal and alloxan-induced diabetic rats," Indian Journal of Pharmacology, vol. 42, no. 4, pp. 224-228, 2010.

[31] B. Nickavar, M. Kamalinejad, and H. Izadpanah, "In vitro free radical scavenging activity of five Salvia species," Pakistan journal of Pharmaceutical Sciences, vol. 20, no. 4, pp. 291-294, 2007.

[32] E. Melo, J. Filho, and N. Guerra, "Characterization of antioxidant compounds in aqueous coriander extracts (Coriander sativumL.)," LWT-Food Science and Technology, vol. 38, pp. 1519, 2005.

[33] B. Elitok, "Efficacy of herbal remedies in the treatment of cardiovascular diseases in human and animals," Kocatepe Veterinary Journal, vol. 6, no. 1, pp. 63-68, 2013.

[34] D. Okwu, F. Morah, and E. Anam, "Isolation and characterization of phenanthrenic alkaloid uvariopsine from Dennettia tripetala fruits," Medicinal and Aromatic Plant Science and Biotechnology, vol. 27, pp. 496-498, 2005.

[35] S. C. Achinewhu, C. C. Ogbonna, and A. D. Hart, "Chemical composition of indigenous wild herbs, spices, fruits, nuts and leafy vegetables used as food," Plant Foods for Human Nutrition, vol. 48, no. 4, pp. 341-348, 1995.

[36] M. Iwu, "Food for medicine," in Dietary Plants And Masticastors as Sources of Biologically Active Substances, pp. 303-310, University of Ife Press, Ife, Nigeria, 1989.

[37] A. Sofowora, Screening Plants for Bioactive Agents. Medical Plants and Traditional Medicinal in Africa, Spectrum Books, Ibadan, Nigeria, 1993.

[38] G. Trease and W. Evans, Parmacognosy, vol. 393, Saunders Publishers, London, UK, 2002. 
[39] J. Harborne, Phytochemical Methods: A Guide to Modern Techniques of Plant Analysis, Chapman and Hall Publishers, London, UK, 2nd edition, 1973.

[40] H. R. Ferdowsian and N. Beck, "Ethical and scientific considerations regarding animal testing and research," PLOS ONE, vol. 6, no. 9, 2011.

[41] D. Lorke, "A new approach to practical acute toxicity testing," Archives of Toxicology, vol. 54, no. 4, pp. 275-287, 1983.

[42] S. Lenzen, "The mechanisms of alloxan- and streptozotocininduced diabetes," Diabetologia, vol. 51, no. 2, pp. 216-226, 2008.

[43] L. Luzi and G. Pozza, "Glibenclamide: an old drug with a novel mechanism of action?" Acta Diabetologica, vol. 34, no. 4, pp. 239-244, 1997.

[44] P. Trinder, "CHOD-PAD enzymatic colorimetric method of cholesterol determination," Annals of Clinical Biochemistry, vol. 6, pp. 24-27, 1969.

[45] P. Fossati and L. Prencipe, "Serum triglycerides determined colorimetrically with an enzyme that produces hydrogen peroxide," Clinical Chemistry, vol. 28, no. 10, pp. 2077-2080, 1982.

[46] D. Fredrickson, R. Levy, and R. Lees, "Fat transport in lipoprotein- an integrated approach to mechanisms and disorders," The New England Journal of Medicine, vol. 276, no. 5, pp. 273281, 1967.

[47] J. J. Albers, G. R. Warnick, and M. C. Chenng, "Quantitation of high density lipoproteins," Lipids, vol. 13, no. 12, pp. 926-932, 1978.

[48] T. Ng, C. The, M. Vidyadaran et al., "A critical evaluation of high density lipoprotein cholesterol as an index of coronary artery disease risk in Malaysians," Malaysian Journal of Nutrition, vol. 3, pp. 61-70, 1997.

[49] J. C. Ozougwu, K. C. Obimba, C. D. Belonwu, and C. B. Unakalamba, "The pathogenesis and pathophysiology of type 1 and type 2 diabetes mellitus," Journal of Physiology and Pathophysiology, vol. 4, no. 4, pp. 46-57, 2013.

[50] I. J. Atangwho, K. B. Yin, M. I. Umar, M. Ahmad, and M. Z. Asmawi, "Vernonia amygdalina simultaneously suppresses gluconeogenesis and potentiates glucose oxidation via the pentose phosphate pathway in streptozotocin-induced diabetic rats," BMC Complementary and Alternative Medicine, vol. 14, no. 1, article 426, 2014.

[51] R. Kumar, D. Kerins, and T. Walther, "Cardiovascular safety of anti-diabetic drugs," European Heart Journal Cardiovascular Pharmacotherapy, vol. 2, pp. 32-43, 2016.

[52] A. Chaudhury, C. Duvoor, V. S. Reddy Dendi et al., "Clinical review of antidiabetic drugs: Implications for type 2 diabetes mellitus management," Frontiers in Endocrinology, vol. 8, no. 6, pp. 1-12, 2017.

[53] R. G. Moses, "Combination therapy for patients with Type 2 diabetes: repaglinide in combination with metformin," Expert Review of Endocrinology and Metabolism, vol. 5, no. 3, pp. 331342, 2010.

[54] M. Unnikrishnan, V. Veerapur, Y. Yogendra Nayak, P. Mudgal, and G. Mathew, "Antidiabetic, antihyperlipidemic and antioxidant effects of the flavonoids," in Polyphenols in Human Health and Disease, vol. 1, pp. 143-161, 2014.

[55] G. Boden, P. Cheung, M. Mozzoli, and S. K. Fried, "Effect of thiazolidinediones on glucose and fatty acid metabolism in patients with type 2 diabetes," Metabolism: Clinical and Experimental, vol. 52, no. 6, pp. 753-759, 2003.

[56] A. J. Krentz and C. J. Bailey, "Oral antidiabetic agents: current role in type 2 diabetes mellitus," Drugs, vol. 65, no. 3, pp. 385411, 2005.
[57] K. Hardy and S. McNutty, "Oral hypoglycaemic agent," Medical Digest, vol. 23, pp. 5-9, 1997.

[58] N. A. Trivedi, B. Mazumdar, J. D. Bhatt, and K. G. Hemavathi, "Effect of shilajit on blood glucose and lipid profile in alloxaninduced diabetic rats," Indian Journal of Pharmacology, vol. 36, no. 6, pp. 373-376, 2004.

[59] R. Vinayagam and B. Xu, "Antidiabetic properties of dietary flavonoids: A cellular mechanism review," Nutrition and Metabolism, vol. 12, no. 1, article 60, 2015.

[60] N. Koffi, F. Yvette, and K. Henri, "Effect of aqueous extract of Boerhaavia diffusa leaves in the glycaemia of rabbits," nternational Journal ofApplied Biology and Pharmaceutical Technology, vol. 2, no. 3, pp. 330-338, 2011.

[61] A. Mungle, M. Bodhankar, and K. Chandak, "Antidiabetic potential of Dolichandrone falcata leaves in alloxan induced diabetic rats," International Journal of Research in Pharmaceutical andBiomedical Sciences, vol. 3, no. 1, pp. 319-324, 2012.

[62] A. K. Singh and J. Singh, "Evaluation of anti-diabetic potential of leaves and stem of Flacourtia jangomas in streptozotocininduced diabetic rats," Indian Journal of Pharmacology, vol. 42, no. 5, pp. 301-305, 2010.

[63] S. P. Sah, M. L. Sah, V. Juyal, and S. Pandey, "Hypoglycemic activity of aqueous extract of Urtica parviflora roxb. in normoglycemic rats," International Journal of Phytomedicine, vol. 2, no. 1, pp. 47-51, 2010.

[64] S. Oyedemi, G. Bradley, and A. Afolayan, "Antidiabetic activities of aqueous stem bark extract of Strychnos henningsii Gilg. in streptozotocin-nicotinamide type 2 diabetic rats," Iranian Journal of Pharmaceutical Research, vol. 11, no. 1, pp. 221-228, 2012.

[65] B. Oliver-Bever, Medicinal Plants in Tropical West Africa, Cambridge University Press, London, UK, 1986.

[66] M. D. Ivorra, M. Payá, and A. Villar, "A review of natural products and plants as potential antidiabetic drugs," Journal of Ethnopharmacology, vol. 27, no. 3, pp. 243-275, 1989.

[67] A. Rhemann and K. Zaman, "medicinal plants with hypoglycaemic activity," Journal of Ethnopharmacology, vol. 26, pp. 1-55, 1989.

[68] B. Kameswara Rao, P. Renuka Sudarshan, M. D. Rajasekhar, N. Nagaraju, and C. Appa Rao, "Antidiabetic activity of Terminalia pallida fruit in alloxan induced diabetic rats," Journal of Ethnopharmacology, vol. 85, no. 1, pp. 169-172, 2003.

[69] J. Girard, P. Ferre, and F. Foufelle, "Mechanism by which carbohydrate regulates expression of genes for glycolytic and lipogenic enzymes," Annual Review of Nutrition, vol. 17, no. 325, 1997.

[70] J. Grimsby, R. Sarabu, W. L. Corbett et al., "Allosteric activators of glucokinase: Potential role in diabetes therapy," Science, vol. 301, no. 5631, pp. 370-373, 2003.

[71] J. A. Pfefferkorn, "Strategies for the design of hepatoselective glucokinase activators to treat type 2 diabetes," Expert Opinion on Drug Discovery, vol. 8, no. 3, pp. 319-330, 2013.

[72] J. J. Hulmi, M. Silvennoinen, M. Lehti, R. Kivelä, and H. Kainulainen, "Altered REDD1, myostatin, and Akt/mTOR/FoxO/ MAPK signaling in streptozotocin-induced diabetic muscle atrophy," The American Journal of Physiology-Endocrinology and Metabolism, vol. 302, no. 3, pp. E307-E315, 2012.

[73] P. Newsholme, F. Abdulkader, E. Rebelato et al., "Amino acids and diabetes: Implications for endocrine, metabolic and immune function," Frontiers in Bioscience, vol. 16, no. 1, pp. 315339, 2011. 
[74] D. J. Glass, "Skeletal muscle hypertrophy and atrophy signaling pathways," International Journal of Biochemistry and Cell Biology, vol. 37, no. 10, pp. 1974-1984, 2005.

[75] A. Musarò, K. McCullagh, A. Paul et al., "Localized Igf-1 transgene expression sustains hypertrophy and regeneration in senescent skeletal muscle," Nature Genetics, vol. 27, no. 2, pp. 195-200, 2001.

[76] M. Miyazaki and K. Esser, "Cellular mechanisms regulating protein synthesis and skeletal muscle hypertrophy in animals," Journal of Applied Physiology, vol. 106, pp. 1367-1373, 2009.

[77] J. Zhang, P. Zhuang, Y. Wang et al., "Reversal of muscle atrophy by Zhimu-Huangbai herb-pair via Akt/mTOR/FoxO3 signal pathway in streptozotocin-induced diabetic mice," PLoS ONE, vol. 9, no. 6, article e100918, 2014.

[78] A. J. Krentz, "Lipoprotein abnormalities and their consequences for patients with type 2 diabetes," Diabetes, Obesity and Metabolism, vol. 5, no. 1, pp. S19-S27, 2003.

[79] A. Shirwaikar, K. Rajendran, C. D. Kumar, and R. Bodla, "Antidiabetic activity of aqueous leaf extract of Annona squamosa in streptozotocin-nicotinamide type 2 diabetic rats," Journal of Ethnopharmacology, vol. 91, no. 1, pp. 171-175, 2004.

[80] B. Kameswararao, M. M. Kesavulu, and C. Apparao, "Evaluation of antidiabetic effect of Momordica cymbalaria fruit in alloxandiabetic rats," Fitoterapia, vol. 74, no. 1-2, pp. 7-13, 2003.

[81] G. F. Lewis, K. D. Uffelman, L. W. Szeto, B. Weller, and G. Steiner, "Interaction between free fatty acids and insulin in the acute control of very low density lipoprotein production in humans," Journal of Clinical Investigation, vol. 95, no. 1, pp. 158-166, 1995.

[82] S. Kehlenbrink, S. Koppaka, M. Martin et al., "Elevated NEFA levels impair glucose effectiveness by increasing net hepatic glycogenolysis," Diabetologia, vol. 55, no. 11, pp. 3021-3028, 2012.

[83] C. Best and N. Taylor, "Biological effect of insulin," in Physiological Basis of Medical Practise, W. William and Wilkin, Eds., pp. 245-267, Cambridge University Press, London, UK, 1989.

[84] P. Strålfors and R. C. Honnor, "Insulin-induced dephosphorylation of hormone-sensitive lipase. Correlation with lipolysis and cAMP-dependent protein kinase activity," European Journal of Biochemistry, vol. 182, no. 2, pp. 379-385, 1989.

[85] M. Jaye, K. J. Lynch, J. Krawiec et al., "A novel endothelialderived lipase that modulates HDL metabolism," Nature Genetics, vol. 21, no. 4, pp. 424-428, 1999.

[86] K.-I. Hirata, H. L. Dichek, J. A. Cioffi et al., "Cloning of a unique lipase from endothelial cells extends the lipase gene family," Journal of Biological Chemistry, vol. 274, no. 20, pp. 14170-14175, 1999.

[87] M. G. McCoy, G.-S. Sun, D. Marchadier, C. Maugeais, J. M. Glick, and D. J. Rader, "Characterization of the lipolytic activity of endothelial lipase," Journal of Lipid Research, vol. 43, no. 6, pp. 921-929, 2002.

[88] Y. Kojima, T. Ishida, L. Sun et al., "Pitavastatin decreases the expression of endothelial lipase both in vitro and in vivo," Cardiovascular Research, vol. 87, no. 2, pp. 385-393, 2010.

[89] R. A. Ortíz Cruz, J. L. Cárdenas López, G. A. González Aguilar et al., "Influence of sorghum kafirin on serum lipid profile and antioxidant activity in hyperlipidemic rats (in vitro and in vivo studies)," BioMed Research International, vol. 2015, Article ID 164725, 8 pages, 2015.

[90] H. Ginsberg, J. Plutzky, and B. E. Sobel, "A review of metabolic and cardiovascular effects of oral antidiabetic agents: beyond glucose-level lowering," Journal of Cardiovascular Risk, vol. 6, no. 5, pp. 337-346, 1999.
[91] H. N. Ginsberg, "Diabetic dyslipidemia: Basic mechanisms underlying the common hypertriglyceridemia and low HDL cholesterol levels," Diabetes, vol. 45, no. 3, pp. S27-S30, 1996.

[92] D. B. Panagiotakos, C. Pitsavos, and J. Skoumas, "Importance of LDL/HDL cholesterol ratio as a predictor for coronary heart disease events in patients with heterozygous familial hypercholesterolaemia: a 15-year follow-up (1987-2002)," Current Medical Research and Opinion, vol. 19, no. 2, pp. 89-94, 2003. 

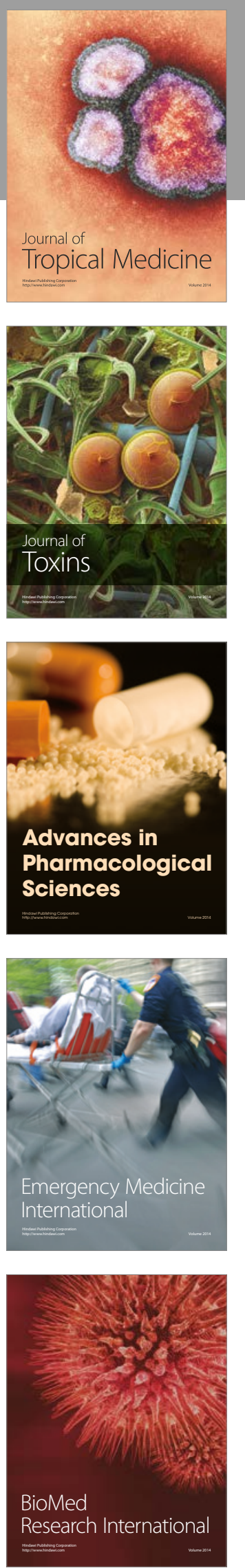
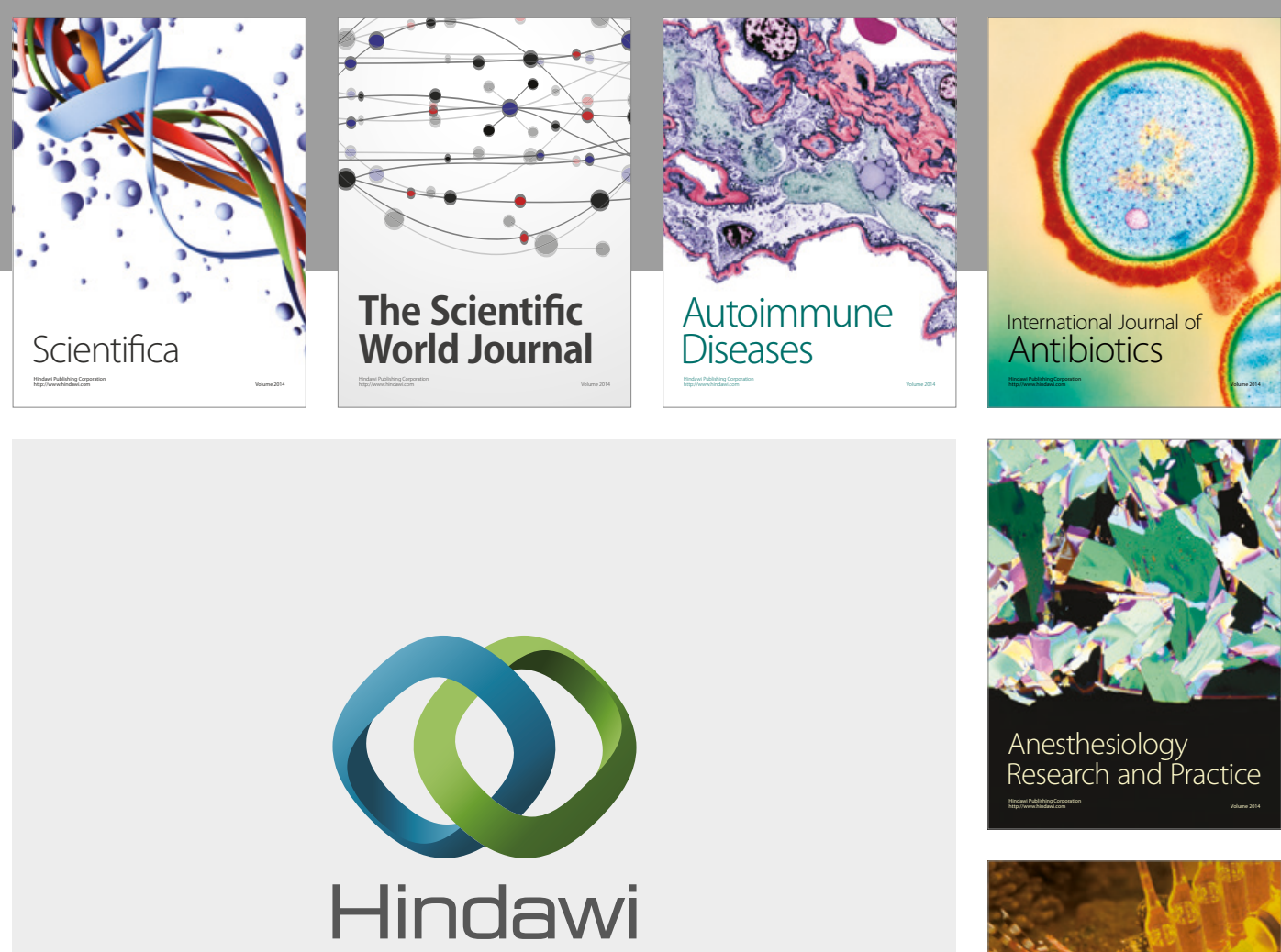

Submit your manuscripts at

https://www.hindawi.com
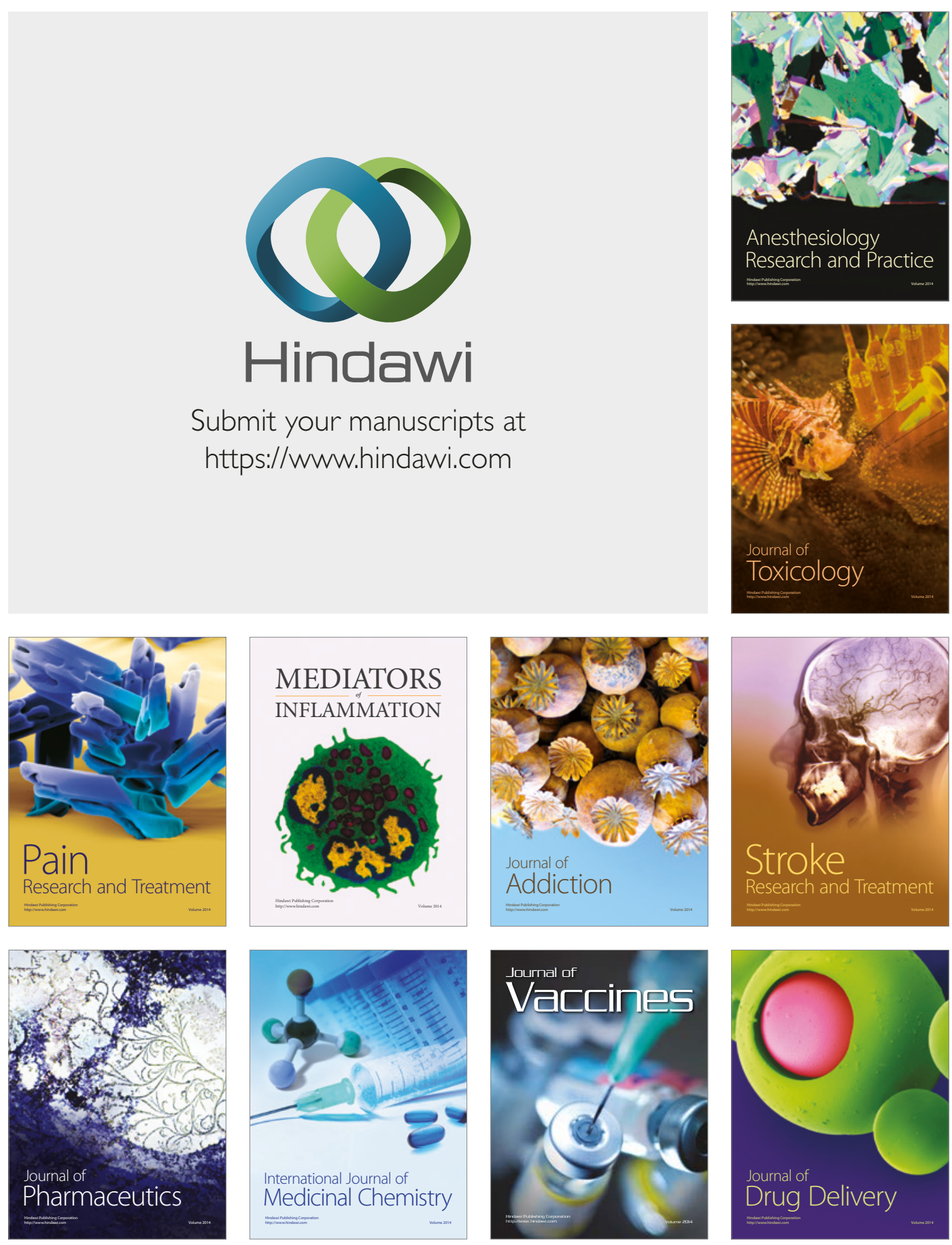